Correspondence

Giancarlo Perrone

giancarlo.perrone@ispa.cnr.it

\section{Aspergillus uvarum sp. nov., an uniseriate black Aspergillus species isolated from grapes in Europe}

\author{
Giancarlo Perrone, ${ }^{1}$ János Varga, ${ }^{2,3}$ Antonia Susca, ${ }^{1}$ Jens C. Frisvad, ${ }^{4}$ \\ Gaetano Stea, ${ }^{1}$ Sándor Kocsubé, ${ }^{2}$ Beáta Tóth, ${ }^{5}$ Zofia Kozakiewicz ${ }^{6}$ \\ and Robert A. Samson ${ }^{3}$
${ }^{1}$ Institute of Sciences of Food Production, CNR, Via Amendola 122/O, 70126 Bari, Italy
${ }^{3}$ CBS Fungal Biodiversity Centre, Uppsalalaan 8, 3584 CT Utrecht, The Netherlands
${ }^{4}$ Center for Microbial Biotechnology, BioCentrum-DTU, Building 221, Technical University of Denmark, DK-2800 Kgs Lyngby, Denmark
${ }^{5}$ Cereal Research non-Profit Company, P.O. Box 391, H-6701 Szeged, Hungary
${ }^{6}$ Institute for Biotechnology and Bioengineering (IBB), Micoteca da Universidade do Minho, Campus de Gualtar, 4710-057 Braga, Portugal \\ ${ }^{2}$ Department of Microbiology, Faculty of Sciences, University of Szeged, H-6701 Szeged, Hungary
}

\begin{abstract}
A novel species, Aspergillus uvarum sp. nov., is described within Aspergillus section Nigri. This species can be distinguished from other black aspergilli based on internal transcribed spacers (ITS), $\beta$-tubulin and calmodulin gene sequences, by AFLP analysis and by extrolite profiles. Aspergillus uvarum sp. nov. isolates produced secalonic acid, common to other Aspergillus japonicus-related taxa, and geodin, erdin and dihydrogeodin, which are not produced by any other black aspergilli. None of the isolates were found to produce ochratoxin A. The novel species is most closely related to two atypical strains of Aspergillus aculeatus, CBS 114.80 and CBS 620.78, and was isolated from grape berries in Portugal, Italy, France, Israel, Greece and Spain. The type strain of Aspergillus uvarum sp. nov. is IMI $388523^{\top}=\mathrm{CBS} 127591^{\top}=$ ITEM $^{2}$ $4834^{\top}=$ IBT $26606^{\top}$.
\end{abstract}

\section{INTRODUCTION}

Black aspergilli (Aspergillus section Nigri; Gams et al., 1985) have a significant impact on modern society. Many species cause food spoilage, and several are used in the fermentation industry to produce hydrolytic enzymes, such as amylases or lipases, and organic acids, such as citric acid and gluconic acid (Varga et al., 2000). They can also be employed for genetic manipulation in the biotechnology industries, for example Aspergillus niger used under certain industrial conditions has been granted GRAS (Generally Regarded As Safe) status by the Food and Drug Administration of the US

Abbreviations: AFLP, amplified fragment length polymorphism; ITS, internal transcribed spacer; NJ, neighbour-joining; SEM, scanning electron microscopy; TBR, tree bisection and reconstruction; UPGMA, unweighted pair group method.

The GenBank/EMBL/DDBJ accession numbers for the $\beta$-tubulin, ITS and calmodulin gene sequences of the strains examined in this study are shown in Table 1. The MycoBank accession number for Aspergillus uvarum sp. nov. is MB 510962 (http://www.mycobank.org).

Phylogenetic trees based on ITS and calmodulin gene sequence data and a dendrogram based on cluster analysis of AFLP data are available with the online version of this paper. government. Although the main habitat of black aspergilli is soil, members of this section have been isolated from various other sources (Kozakiewicz, 1989; Abarca et al., 2004; Samson et al., 2004). Apart from their economical importance, black aspergilli are also important as ochratoxinproducing organisms which contaminate several agricultural products, including grape-derived products, coffee and cocoa (Cabañes et al., 2002; Samson et al., 2004; Battilani et al., 2006 and other papers in this special issue).

In spite of their importance, the taxonomy of this section is still not completely resolved and the species distribution in food is often not clearly reported. Black aspergilli are one of the more difficult groups to classify and identify and the taxonomy of Aspergillus section Nigri has been studied by many taxonomists (Abarca et al., 2004; Varga et al., 2007). Nuclear and mitochondrial DNA (mtDNA) polymorphisms and PCR-based techniques led to the recognition of at least two species within the $A$. niger species complex (A. niger and Aspergillus tubingensis) (Kusters-van Someren et al., 1991; Varga et al., 1994). Phylogenetic analyses of sequences of the internal transcribed spacers region (ITS), the 5.8S rRNA gene and the D1-D2 region of the $28 \mathrm{~S}$ rRNA gene indicated that, 
in addition to A. niger and A. tubingensis, at least five other species belong to section Nigri: Aspergillus heteromorphus, Aspergillus ellipticus, Aspergillus carbonarius, Aspergillus japonicus and Aspergillus aculeatus (Varga et al., 2000; Parenicova et al., 2001). Several other black Aspergillus species have been described recently, including Aspergillus vadensis (de Vries et al., 2005), Aspergillus costaricaensis, Aspergillus piperis, Aspergillus lacticoffeatus and Aspergillus sclerotioniger (Samson et al., 2004), Aspergillus ibericus (Serra et al., 2006) and Aspergillus brasiliensis (Varga et al., 2007).

During a molecular survey of black Aspergillus isolates collected from 107 vineyards in different European countries within the EU project Wine-Ochra Risk (QLK1-CT-200101761), we discovered a group of uniseriate aspergilli morphologically very similar to the well-recognized species A. japonicus and A. aculeatus, but clearly separated by amplified fragment length polymorphism (AFLP) molecular analysis (Perrone et al., 2006). In this paper, we analyse the relationships of these isolates to other aspergilli using molecular and chemotaxonomic approaches, and describe these isolates as a novel species, Aspergillus uvarum sp. nov.

\section{METHODS}

The strains of the novel species examined are listed in Table 1. The morphology of these strains was re-examined according to Raper \& Fennell (1965) and Kozakiewicz (1989). The strains were maintained on malt extract autolysate (MEA) agar slants. The 28 Aspergillus section Nigri strains listed in Table 2 were used as reference strains for sequences and AFLP comparison analyses, and the type strain of Aspergillus flavus CBS $100927^{\mathrm{NT}}$ was used as an outgroup.

Morphological analysis. For macromorphological observations, Czapek yeast autolysate (CYA), MEA agar, Czapek agar (CZA) (Samson et al., 2004) and G25N agar (Pitt, 1979) were used. Czapek agar with $20 \%$ sucrose (CZ20) and malt and yeast extract agar with $40 \%$ sucrose (M40Y) were made as described previously (Raper \& Fennell, 1965). Growth rates were studied and compared with reference strains for 7 days on CYA at 5, 25 and $37^{\circ} \mathrm{C}$, on G25N, CZA and MEA at $25{ }^{\circ} \mathrm{C}$ in the dark. Cultures were also grown on $\mathrm{CZ} 20$ and M40Y for 7 days at $25^{\circ} \mathrm{C}$ in the dark to assess growth on media with reduced water activity. For micromorphological observations, microscopic mounts were made in lactic acid from MEA colonies and a drop of alcohol was added to remove air bubbles and excess conidia. Scanning electron microscopy (SEM) was performed with uncoated frozen samples and micrographs consisted of 30 averaged fast scans (SCAN 2 mode) in a JEOL 5600LV scanning electron microscope equipped with an Oxford CT1500 cryostation.

Extrolite analysis. Extrolites were analysed by HPLC using alkylphenone retention indices and diode array UV-VIS detection as described by Frisvad \& Thrane (1987), with modifications as described by Smedsgaard (1997). Standards of ochratoxin A and B, aflavinine, asperazine, austdiol, kotanin, asterric acid, secalonic acid $\mathrm{D}$, neoxaline and roquefortine $\mathrm{D}$ from the collection at BioCentrumDTU (Danish Technical University) were used for comparison with the extrolites from the strains under study.

Isolation and analysis of nucleic acids. Forty-four strains representative of the uniseriate black aspergilli isolated from grapes were analysed by sequence analysis together with 27 representative strains of section Nigri. Total nucleic acids were isolated as described previously (Leach et al., 1986). Fragments containing the region encoding the internal transcribed spacer 1 (ITS-1), 5.8S rDNA and internal transcribed spacer 2 (ITS-2) were amplified using primers ITS1 and ITS4 as described previously (White et al., 1990). Amplification of part of the $\beta$-tubulin gene was performed using the primers $\mathrm{Bt} 2 \mathrm{a}$ and Bt2b (Glass \& Donaldson, 1995; Samson et al., 2004). Amplifications of the partial calmodulin gene were set up as described previously (Perrone et al., 2004). Sequence analysis was performed with the Big Dye Terminator Cycle Sequencing Ready reaction kit for both strands, and the sequences were aligned with the MT Navigator software (Applied Biosystems). All the sequencing reactions were purified by gel filtration through Sephadex G-50 (Amersham Pharmacia Biotech) equilibrated in double-distilled water and analysed on an ABI PRISM 3100 Genetic Analyzer (Applied Biosystems). Representative ITS, $\beta$-tubulin and calmodulin sequences were deposited at the GenBank nucleotide sequence database (Table 1).

AFLP analysis. Seventy-nine strains, 54 uniseriate Aspergillus isolates from grapes and 25 isolates belonging to different species of Aspergillus section Nigri, were analysed by AFLP analysis (Tables 1 and 2). Fungal strain growth and relative DNA isolation were done according to Perrone et al. (2006).

Fluorescent AFLP was performed as described in the AFLP microbial fingerprinting kit protocol (Applied Biosystems). Four separate primer combinations were utilized for the selective amplifications: $\mathrm{EcoRI}+\mathrm{AC}$ and $\mathrm{MseI}+\mathrm{CC}, \mathrm{EcoRI}+\mathrm{AT}$ and $\mathrm{Mse} \mathrm{I}+\mathrm{CG}, \mathrm{EcoRI}+\mathrm{AC}$ and $\mathrm{MseI}+\mathrm{CA}$ and $\mathrm{EcoRI}+\mathrm{G}$ and $\mathrm{Mse} \mathrm{I}+\mathrm{CT}$. GeneScan-500 (ROX) was used as internal size standard (Applied Biosystems). The product was separated by capillary electrophoresis on an ABI PRISM 310 Genetic Analyzer (Applied Biosystems). After electrophoresis, the pattern was extracted with the GeneScan version 3.1.2 software (Applied Biosystems) and the fingerprints were automatically analysed with the Genotyper software (Applied Biosystems). To test the reproducibility of the method, DNA of five strains was isolated from three replicate cultures and tested separately in triplicate. DNA of remaining strains was tested in duplicate.

Peak height thresholds were set at 200. Genotyper software (Applied Biosystems) was set to medium smoothing. Bands of the same size in different individuals were assumed to be homologous and to represent the same allele. Bands of different size were treated as independent loci with two alleles. Data were analysed with the AFLP Manager database (ACGT BioInformatica) and were exported in a binary format with ' 1 ' for presence of a peak and ' 0 ' for its absence. For clustering, two different analyses were performed: fragments between 100 and $500 \mathrm{bp}$ and fragments between 200 and $500 \mathrm{bp}$ were analysed with NTSYSPc software (Exeter Software) by using the Dice similarity coefficient and clustered by the unweighted pair group method (UPGMA) (Nei \& Li, 1979). A. flavus CBS $100927^{\mathrm{NT}}$ was used as an outgroup in these experiments.

Analysis of sequence data. The alignment of ITS regions, partial $\beta$ tubulin and calmodulin gene sequence data was performed using the software package BioNumerics (Applied Maths) and manual adjustments were made where necessary.

Phylogenetic trees were prepared by the neighbour-joining (NJ) method (Saitou \& Nei, 1987) using the program NEIGHBOR of the PHYLIP package. Bootstrap values were calculated from 1000 replications of the bootstrap procedure using programs SEQBOOT, DNADIST, NEIGHBOR and CONSENSE of the PHYLIP package (Felsenstein, 1985; 1995). For parsimony analysis, the PAUP* version 4.0 software was used (Swofford, 2000). Alignment gaps were treated as a fifth character state and all characters were unordered and of equal weight. Maximum-parsimony analysis was performed for all datasets using the heuristic search option with 100 random taxa additions and tree bisection and reconstruction (TBR) as the branch-swapping 
algorithm. Branches of zero length were collapsed and all multiple, equally parsimonious trees were saved. The robustness of the trees obtained was evaluated by 1000 bootstrap replications (Hillis \& Bull, 1993). A. flavus CBS $100927^{\mathrm{NT}}$ was used as an outgroup in these experiments.

\section{RESULTS AND DISCUSSION}

Several uniseriate black Aspergillus strains were isolated from grape berries in the Mediterranean area, mainly from Italy, France and Israel. They were found to be related to $A$. japonicus, based on morphological data, and none of these A. japonicus-related isolates produced ochratoxin A. Morphologically, A. uvarum sp. nov. is most closely related to $A$. japonicus. However, both vesicle and conidium sizes are somewhat smaller in A. uvarum sp. nov. For example, vesicle size in A. uvarum sp. nov. ranges from 20 to $30 \mu \mathrm{m}$ diameter, whereas for A. japonicus they average 20-30 $\mu \mathrm{m}$, but can be as large as $45 \mu \mathrm{m}$. Conidial shape is similar, namely subglobose to globose, but $A$. japonicus conidia are mostly $3.0-4.5 \mu \mathrm{m}$, compared with $3.0-4.0 \mu \mathrm{m}$ for $A$. uvarum sp. nov. A. aculeatus has much larger conidial heads with vesicles ranging from 22 to $55 \mu \mathrm{m}$ in diameter and conidia which are ellipsoidal in shape.

However, it is growth rates, particularly on CYA at $37^{\circ} \mathrm{C}$, which clearly separate $A$. uvarum sp. nov. from $A$. japonicus and $A$. aculeatus. Growth of $A$. uvarum sp. nov. is much slower, with colony diameters after 7 days growth ranging from $16 \mathrm{~mm}$ for isolates A. uvarum sp. nov. IMI 388537 and IMI 388671 to $23 \mathrm{~mm}$ for isolates IMI 388523, IMI 388537 and IMI 388671. Colony diameters for A. japonicus CBS $114.51^{\mathrm{NT}}$ and A. aculeatus IMI $211388^{\mathrm{T}}$ were $30 \mathrm{~mm}$ after 7 days. These morphological and physiological differences, together with the extrolite and molecular information discussed below, indicate that A. uvarum sp. nov. is a novel uniseriate species within section Nigri.

Furthermore, these isolates could readily be distinguished from other uniseriate black aspergilli by AFLP analysis (Perrone et al., 2006). We examined the genetic relatedness of some selected isolates (Table 1) to other black aspergilli, analysing nucleotide sequences of partial rDNA (ITS-1, $5.8 \mathrm{~S}$ and ITS-2), calmodulin and $\beta$-tubulin genes. The $\beta$ tubulin dataset included 551 characters, with 161 parsimony-informative characters. The $\mathrm{NJ}$ tree based on partial $\beta$-tubulin gene sequences is shown in Fig. 1.

The topology of the $\beta$-tubulin tree is the same as that of a parsimony tree constructed by the PAUP ${ }^{*}$ program (length: 437 steps, consistency index: 0.6865, retention index: 0.8880 ). The ITS dataset included 475 characters with 72 parsimony-informative characters. The NJ tree based on ITS sequence data, shown in Supplementary Fig. S1 (available in IJSEM Online), has the same topology as the ITS parsimony tree (tree length: 168, consistency index: 0.9048 , retention index: 0.9615$)$. The calmodulin dataset included 666 characters, with 272 parsimony-informative characters. The topologies of the calmodulin NJ tree (Supplementary Fig. S2) and the parsimony tree were the same (tree length: 664, consistency index: 0.7229, retention index: 0.8999).

Although sequence analysis of the ITS region placed all of the uniseriate black aspergilli into the same clade, the $\beta$ tubulin and calmodulin sequence data both indicate the presence of three, closely related uniseriate taxa. In fact, these isolates formed a monophyletic clade supported by high bootstrap values on phylogenetic trees based on $\beta$ tubulin and calmodulin sequence data (Fig. 1 and Supplementary Fig. S2), despite a difference in topology of the two trees in the concordant branches which identified the closely related taxa $A$. aculeatus and $A$. japonicus. The grape-derived isolates were found to be closely related to the atypical ' $A$. aculeatus' isolates CBS 114.80 and CBS 620.78. These isolates, together with recent isolates from Thai coffee beans, represent another novel species in section Nigri (P. Noonim, R. A. Samson and J. Varga, unpublished data).

The grape-derived isolates also formed a well-defined cluster on the UPGMA tree obtained from AFLP data (Supplementary Fig. S3) relative to four-primer combination assays. Our data indicate that these isolates are well separated from other black aspergilli, based on all molecular approaches used. Specific polymorphisms, within and between species, were observed by AFLP. Each primer combination consistently distinguished the 16 different species of Aspergillus species of section Nigri: similarity obtained among species analysed was less than $20 \%$ (Supplementary Fig. S3). All the strains belonging to the same species shared more than $50 \%$ of peaks. The Aspergillus uvarum cluster consists of a main group, including 48 strains clustered at $64 \%$ similarity, and 6 strains (4958, 4959, 4961, 5287, 4997 and 4848), having $52 \%$ similarity with the others (Supplementary Fig. S3).

Extrolite profiles of these isolates were characteristic and unique among the black aspergilli. The isolates of the new taxon proposed below produce secalonic acid D and $\mathrm{F}$ in common with $A$. aculeatus, but produced geodin, erdin, dihydrogeodin and asterric acid, which are not seen in any other black aspergilli. Geodin, erdin, dihydrogeodin and asterric acid are characteristic extrolites of Aspergillus terreus (Raistrick \& Smith, 1936) and Penicillium glabrum (Mahmoodian \& Stickings, 1964; Sato et al., 2005) and are related to trypacidin and monomethylsulochrin, produced by Aspergillus fumigatus (Turner, 1965; Larsen et al., 2007).

An examination of the extrolite profiles of the uniseriate black aspergilli showed that $A$. aculeatus produced secalonic acid $\mathrm{D}$ and $\mathrm{F}$ and physcion, A. japonicus isolates produced festuclavine and cycloclavin and the novel species produced secalonic acid D and F, asterric acid, erdin, geodin and dehydrogeodin. The isolate identified as an atypical A. aculeatus, CBS 114.80, produced okaramine A, $\mathrm{B}, \mathrm{H}$ and I; Aspergillus brunneoviolaceus CBS $621.78^{\mathrm{T}}$ produced okaramines, secalonic acid $\mathrm{D}$ and neoxaline and CBS 620.78 produced secalonic acid D and F, roquefortine $\mathrm{D}$ and some unique indole alkaloids. This is in agreement 
Table 1. Aspergillus uvarum sp. nov. isolates from grapes examined

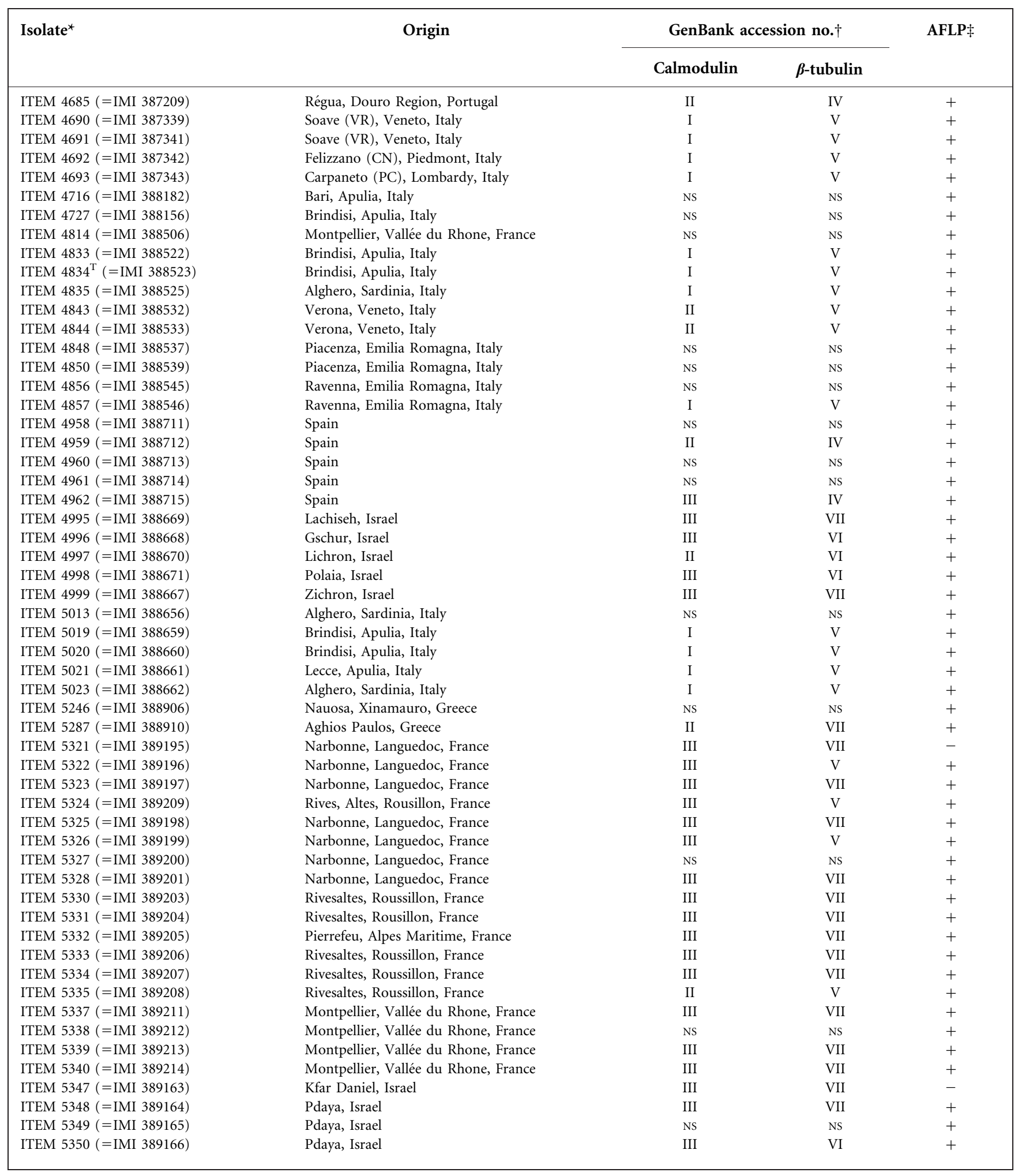

NS, not sequenced.

${ }^{\star}$ IMI, CABI Bioscience Genetic Resource Collection, Egham, UK; ITEM, Agri-Food Toxigenic Fungi Culture Collection, Institute of Sciences of Food Production, Bari, Italy.

$\dagger$ ITS sequences are identical in all strains to ITEM 4834 (GenBank accession no. AM745757). Sequences identical to the deposited GenBank accession numbers are grouped as follows: I, AM745755; II, AM745754; III, AM745756; IV, AM745750; V, AM745751; VI, AM745752; VII, AM745753.

$\ddagger$ Strains subjected $(+)$ or not $(-)$ to AFLP analysis. 
with the separation of these isolates suggested by molecular results (Fig. 1, Supplementary Figs S2 and S3). Thus both extrolite profiles and molecular data indicate that five species can be differentiated in the uniseriate black aspergilli. The isolates of $A$. aculeatus and A. japonicus examined and the new species described here were consistent in their production of extrolites, and thus can be easily differentiated chemically. Based on common production of secalonic acid D and $\mathrm{F}$, the novel species (represented by ITEM $4834^{\mathrm{T}}$ ) appears to be more closely related to $A$. aculeatus than to $A$. japonicus.

Our findings were based on a polyphasic approach to the species concept in Aspergillus (Frisvad \& Samson, 2004). A novel species is different from any other species in a diagnostic sense in both phenotypic and genotypic features. Here we have used morphological, physiological and chemotaxonomic features to characterize the phenotype and sequencing of three genes combined with AFLP results to characterize the isolates genotypically. Since the isolates were unique with regard to morphology, extrolite profiles and genotypic features, we propose the name Aspergillus uvarum sp. nov. for these isolates.

\section{Description of Aspergillus uvarum Perrone, Varga et Kozakiewicz sp. nov. Fig. 2.}

Coloniae in agaro Czapekii celeritercrescentes in septem dies $25{ }^{\circ} \mathrm{C}, 90 \mathrm{~mm}$ diametro attigentes, granulosae, superficie brunnea-nigra, facie inferiore primo alba, deinde obscure ochraceae; exudata non conspicuosa, con solubis pigmentis ochraceis. Sclerotia producta, brunnea usque nigra, globosa vel verticale elongata. Conidiogenesis abundanta. Capitula conidica radiantia, in columnas aegre formatas fissantia, 200-300 $\mu \mathrm{m}$ diametro. Stipites leves incoloures, superne pallide ochracei, 500-1000 $\mu \mathrm{m}$ longissimi, parie plerumque 5-10 $\mu \mathrm{m}$ crassis; vesiculae globosae vel ellipticae 20-30 $\mu \mathrm{m}$ diametro, per toto fertilibus. Aspergilla uniseriata; phialides 5-7 $\times 2.5-3.0 \mu \mathrm{m}$. Conidia brunnea-nigra oculo nudo visa, globosa vel subglobosa, 3-4 $\mu \mathrm{m}$, conspicue spinulosa in maturitate et spinis $0.5 \mu \mathrm{m}$ projecti.

Typus siccus in herb. IMI $388523^{\mathrm{T}}\left(=\mathrm{CBS} 127591^{\mathrm{T}}=\mathrm{ITEM}\right.$ $4834^{\mathrm{T}}=\mathrm{IBT} 26606^{\mathrm{T}}$ ) et ex-typus vivus, isolatus e botrys, Brundisium, Italia.

\section{Description of Aspergillus uvarum Perrone, Varga et Kozakiewicz sp. nov.}

Aspergillus uvarum (u.va'rum. L. masc. adj. uvarum of grapes).

Colonies grow rapidly on Czapek agar, attaining $90 \mathrm{~mm}$ diameter within 7 days at $25{ }^{\circ} \mathrm{C}$, granular, upper surface brown-black; reverse white, wrinkled, becoming dull yellow with age with black colony centres; a soluble pale-yellow pigment is produced; exudate not conspicuous. Sclerotia produced in some fresh isolates, dark brown to black, globose to vertically elongated. Abundant conidiogenesis.
Table 2. Aspergillus section Nigri strains used in this study

CBS, Centraalbureau voor Scimmelcultures, Utrecht, The Netherlands; JHC, James H. Croft's culture collection, Birmingham, UK; IMI, CABI Bioscience Genetic Resource Collection, Egham, UK; ITEM, Agri-Food Toxigenic Fungi Culture Collection, Institute of Sciences of Food Production, Bari, Italy; IBT, Center for Microbial Biotechnology, BioCentrum-DTU, Lyngby, Denmark; NRRL, Agricultural Research Service Culture Collection, National Center for Agricultural, Utilization Research, Peoria, IL, USA.

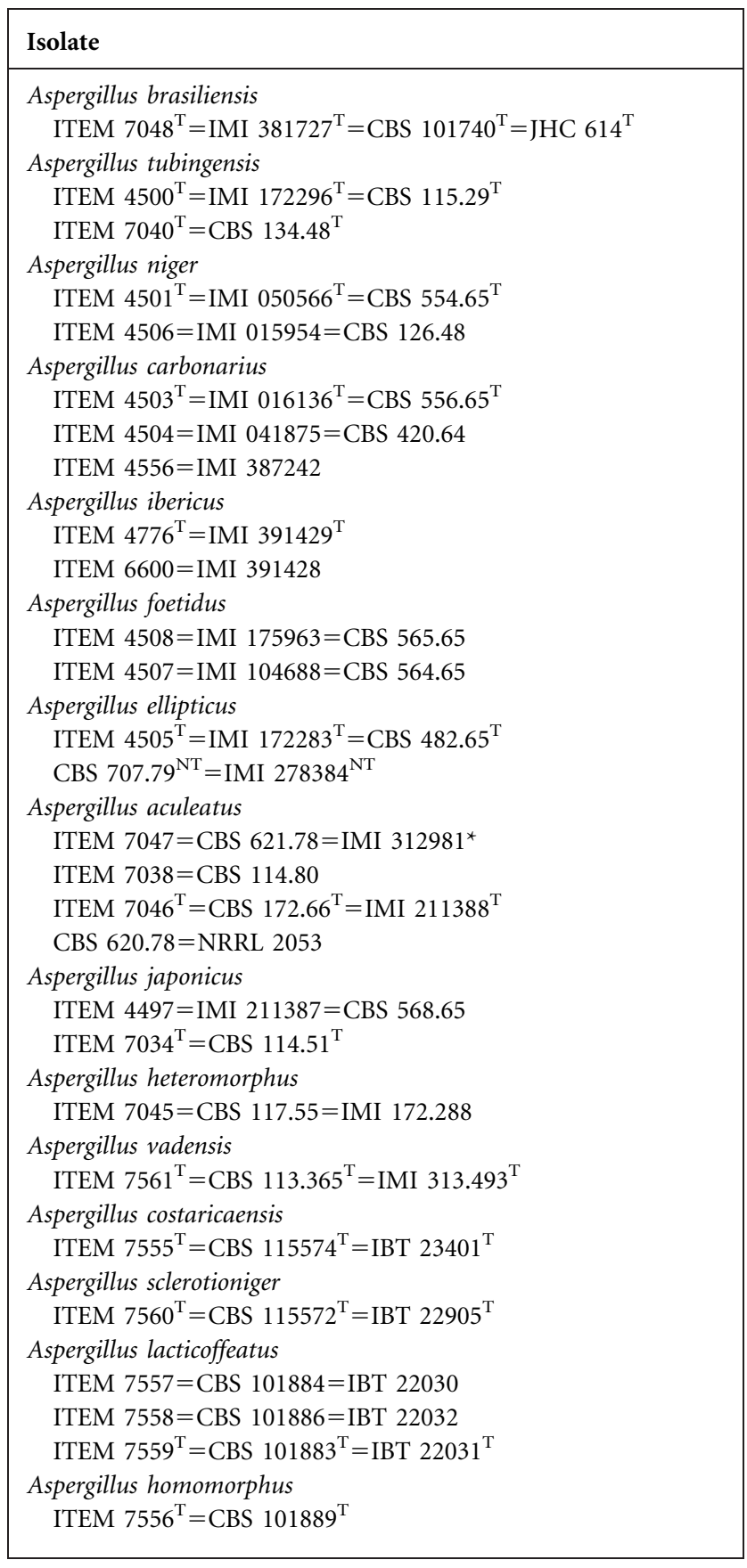

*Type of A. brunneoviolaceus. 


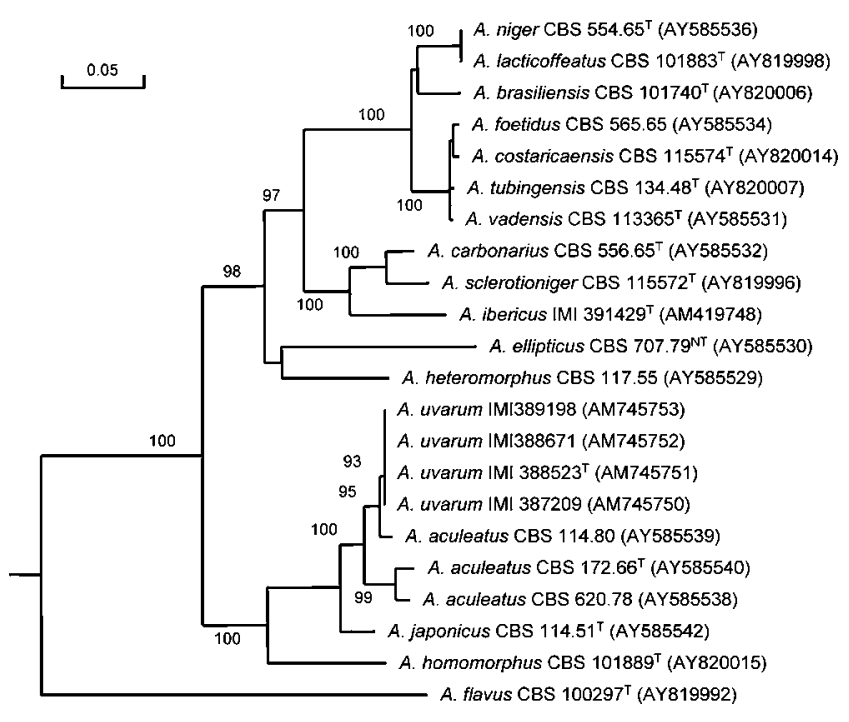

Fig. 1. Phylogenetic tree based on $\beta$-tubulin sequence data of Aspergillus section Nigri. Numbers next to nodes are bootstrap values. Only values above $70 \%$ are indicated. Bar, changes per nucleotide position.

Conidial heads radiate, splitting into poorly defined columns as they age, $200-300 \mu \mathrm{m}$ in diameter. Stipes smooth, $500-1000 \times 5-10 \mu \mathrm{m}$, uncoloured, upper portion light yellowish-brown; vesicles globose to elliptical, 20$30 \mu \mathrm{m}$, fertile over the entire surface. Aspergilli uniseriate; phialides $5-7 \times 2.5-3.0 \mu \mathrm{m}$. Conidia brown-black when seen with the naked eye, globose to subglobose, 3-4 $\mu \mathrm{m}$, conspicuously spinose at maturity with spines projecting $0.5 \mu \mathrm{m}$.

Colonies grown for 7 days at $25{ }^{\circ} \mathrm{C}$ on CYA overgrow a $90 \mathrm{~mm}$ plate. Sclerotia produced by some fresh isolates, usually coloured black. Abundant conidiogenesis. Conidial heads brown-black, mycelium white, usually inconspicuous; exudate inconspicuous; reverse pale or dull yellow with black colony centres; pale-yellow soluble pigment produced. When grown at $37^{\circ} \mathrm{C}$ on CYA colonies attain (14) $16-22 \mathrm{~mm}$ diameter and are identical to colonies grown at $25{ }^{\circ} \mathrm{C}$. When grown on G25N, colonies attain 13-17 $\mathrm{mm}$ diameter but otherwise are identical to those on CYA at $25{ }^{\circ} \mathrm{C}$. No growth or germination is observed at $5{ }^{\circ} \mathrm{C}$. On M40Y and CZ20 colonies are overgrown $\left(90 \mathrm{~mm}\right.$ plates) in 7 days at $25{ }^{\circ} \mathrm{C}$, and are identical to those grown on CYA at $25^{\circ} \mathrm{C}$. Colonies on MEA are overgrown ( $90 \mathrm{~mm}$ plates) after 7 days at $25{ }^{\circ} \mathrm{C}$; conidia brown-black, mycelium inconspicuous; reverse orange-brown, otherwise as on CYA.

Colony colours and texture. On MEA conidiophores are abundantly produced, conidial areas are dark brown; sclerotia absent. Reverse on MEA light yellow, furrowed.

Sequence data. All Aspergillus uvarum sp. nov. strains examined have high sequence similarity inside the group:

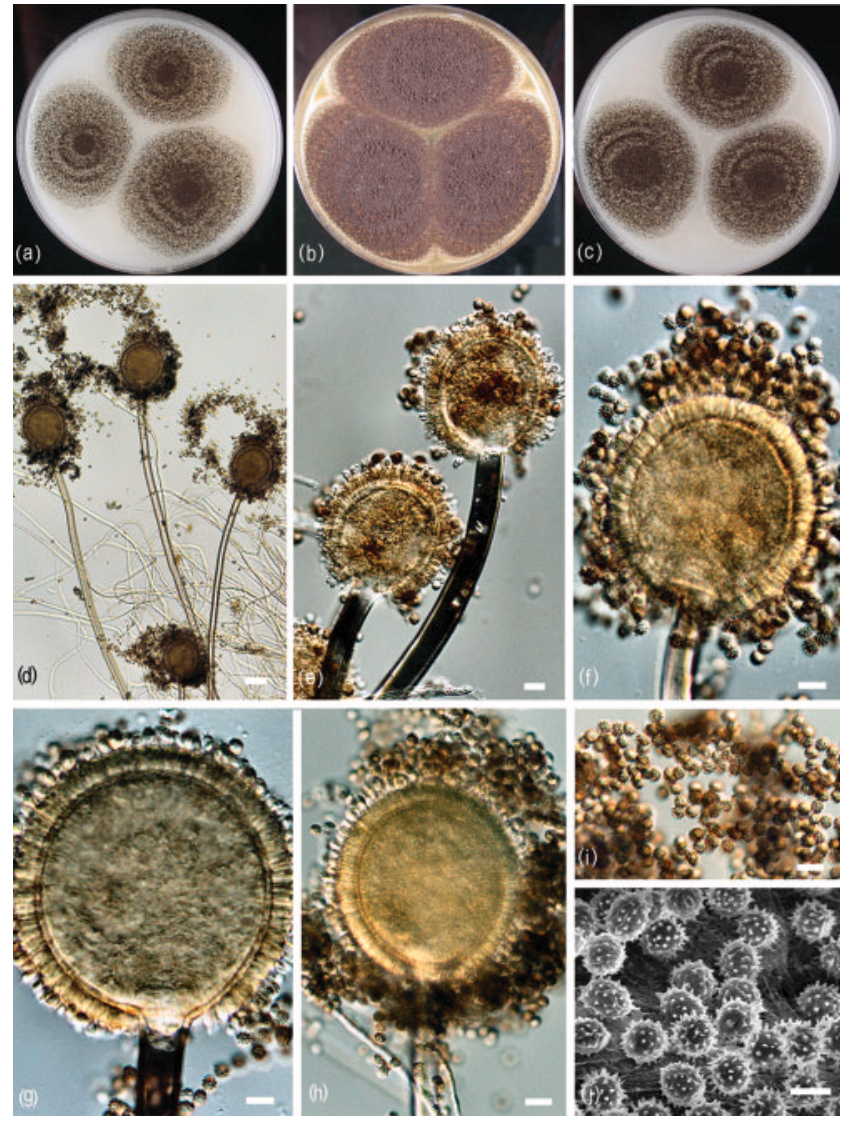

Fig. 2. Aspergillus uvarum sp. nov. IMI $388523^{\top}$. (a) Colonies on CYA, (b) colonies on MEA, (c) colonies on oatmeal agar, (d-h) conidiophores, (i) conidia under light microscopy, (j) conidia as seen using SEM. Bars, $10 \mu \mathrm{m}(\mathrm{e}-\mathrm{h}), 100 \mu \mathrm{m}(\mathrm{d})$ and $5 \mu \mathrm{m}$ (j).

$100 \%$ for ITS, $99.5 \%$ (four groups of individual variability) for the $\beta$-tubulin gene and $99.8 \%$ (three groups of individual variability) for the calmodulin gene. The interspecific sequence divergences in the ITS region between these isolates and A. aculeatus, $A$. japonicus and Aspergillus homomorphus are 0.3, 0.5 and $6.5 \%$, respectively. In the $\beta$-tubulin dataset the differences are higher, in the range $10-18 \%$ for $A$. aculeatus and $A$. japonicus and $25 \%$ for A. homomorphus; while, in the calmodulin dataset, the differences are in the range 4-7\% for A. aculeatus and A. japonicus and $15.8 \%$ for $A$. homomorphus.

Extrolites. All isolates produced secalonic acid D and F, asterric acid, geodin, erdin and dihydrogeodin.

Holotype. Dried colonies of IMI 388523 after 7 days growth on CZA, deposited in the Herbarium of CABI (UK Centre), Egham, UK, formerly International Mycological Institute. Ex-type culture: IMI 388523.

Known distribution. Mediterranean basin, Europe. 


\section{ACKNOWLEDGEMENTS}

We thank Filomena Epifani from Institute of Sciences of Food Production, CNR, Bari, Italy, for his valuable technical assistance, Paola Battilani (Italy), Armando Venancio (Portugal), Elefterios Tjamos (Greece), Amnon Licther (Israel), Vicente Sanchis (Spain) and Ahmed Lebrihi (France) for providing most of the A. uvarum sp. nov. strains used. This research was supported in part by a grant from the Italian Ministry of Education, University and Research (MIUR) Project 12818 - SIVINA - 'Individuazione di metodologie innovative prontamente trasferibili per migliorare la sicurezza dei vini rossi di qualità del Salento'. B.T. was supported by a Bolyai research fellowship grant.

\section{REFERENCES}

Abarca, M. L., Accensi, F., Cano, J. \& Cabanes, F. J. (2004). Taxonomy and significance of black aspergilli. Antonie Van Leeuwenhoek 86, 33-49.

Battilani, P., Logrieco, A. \& Magan, N. (2006). Introductory note. Int J Food Microbiol 111 (Suppl. 1), S1.

Cabañes, F. J., Accensi, F., Bragulat, M. R., Abarca, M. L., Castella, G., Minguez, S. \& Pons, A. (2002). What is the source of ochratoxin A in wine? Int J Food Microbiol 79, 213-215.

de Vries, R. P., Frisvad, J. C., van de Vondervoort, P. J. I., Burgers, K., Kuijpers, A. F. A., Samson, R. A. \& Visser, J. (2005). Aspergillus vadensis, a new species of the group of black Aspergilli. Antonie Van Leeuwenhoek 87, 195-203.

Felsenstein, J. (1985). Confidence limits on phylogenies: an approach using the bootstrap. Evolution 39, 783-791.

Felsenstein, J. (1995). PHYLIP (phylogeny inference package), version 3.57c. Distributed by the author. Department of Genome Sciences, University of Washington, Seattle, USA.

Frisvad, J. C. \& Samson, R. A. (2004). Polyphasic taxonomy of Penicillium subgenus Penicillium. A guide to identification of food and air-borne terverticillate Penicillia and their mycotoxins. Stud Mycol 49, 1-174.

Frisvad, J. C. \& Thrane, U. (1987). Standardized high performance liquid chromatography of 182 mycotoxins and other fungal metabolites based on alkylphenone retention indices and UV-VIS spectra (diode-array detection). J Chromatogr 404, 195-214.

Gams, W., Christensen, M., Onions, A. H. S., Pitt, J. I. \& Samson, R. A. (1985). Infrageneric taxa of Aspergillus. In Advances in Penicillium and Aspergillus Systematics, pp. 55-61. Edited by R. A. Samson \& J. I. Pitt. New York: Plenum Press.

Glass, N. L. \& Donaldson, G. C. (1995). Development of primer sets designed for use with the PCR to amplify conserved genes from filamentous ascomycetes. Appl Environ Microbiol 61, 1323-1330.

Hillis, D. M. \& Bull, J. J. (1993). An empirical test of bootstrapping as a method for assessing confidence in phylogenetic analysis. Syst Biol 42, 182-192.

Kozakiewicz, Z. (1989). Aspergillus species on stored products. Mycological Papers, vol. 161. Wallingford, UK: CABI Publishing.

Kusters-van Someren, M. A., Samson, R. A. \& Visser, J. (1991). The use of RFLP analysis in classification of the black Aspergilli: reinterpretation of the Aspergillus niger aggregate. Curr Genet 19, $21-26$.

Larsen, T. O., Smedsgaard, J., Nielsen, K. F., Hansen, M. A., Samson, R. A. \& Frisvad, J. C. (2007). Production of mycotoxins by Aspergillus lentulus and other medically important and closely related species in section Fumigati. Med Mycol 45, 225-232.
Leach, J., Finkelstein, D. B. \& Rambosek, J. A. (1986). Rapid miniprep of DNA from filamentous fungi. Fungal Genet Newslett 33, 32-33.

Mahmoodian, A. \& Stickings, C. E. (1964). Studies in the biochemistry of micro-organisms. 115. Metabolites of Penicillium frequentans Westling: isolation of sulochrin, asterric acid, (+)bisdechlorogeodin and two new substituted anthraquinones, questin and questinol. Biochem J 92, 369-378.

Nei, M. \& Li, W. H. (1979). Mathematical model for studying genetic variation in terms of restriction endonucleases. Proc Natl Acad Sci U S A 76, 5269-5273.

Parenicova, L., Skouboe, P., Frisvad, J., Samson, R. A., Rossen, L., Hoor-Suykerbuyk, M. \& Visser, J. (2001). Combined molecular and biochemical approach identifies Aspergillus japonicus and Aspergillus aculeatus as two species. Appl Environ Microbiol 67, 521-527.

Perrone, G., Susca, A., Stea, G. \& Mule, G. (2004). PCR assay for identification of Aspergillus carbonarius and Aspergillus japonicus. Eur J Plant Pathol 110, 641-649.

Perrone, G., Mulè, G., Susca, A., Battilani, P., Pietri, A. \& Logrieco, A. (2006). Ochratoxin A production and AFLP analysis of Aspergillus carbonarius, Aspergillus tubingensis, and Aspergillus niger strains isolated from grapes in Italy. Appl Environ Microbiol 72, 680-685.

Pitt, J. I. (1979). The Genus Penicillium and its Teleomorphic States Eupenicillium and Talaromyces. London: Academic Press.

Raistrick, H. \& Smith, G. (1936). Studies in the biochemistry of micro-organisms: The metabolic products of Aspergillus terreus Thom. Part II. Two new chlorine-containing mould metabolic products, geodin and erdin. Biochem J 30, 1315-1322.

Raper, K. B. \& Fennell, D. I. (1965). The Genus Aspergillus. Baltimore, MD: Williams \& Wilkins.

Saitou, N. \& Nei, M. (1987). The neighbor-joining method: a new method for reconstructing phylogenetic trees. Mol Biol Evol 4, 406-425.

Samson, R. A., Houbraken, J. A. M. P., Kuijpers, A. F. A., Frank, J. M. \& Frisvad, J. C. (2004). New ochratoxin or sclerotium producing species in Aspergillus section Nigri. Stud Mycol 50, 45-61.

Sato, S., Okusa, N., Ogawa, A., Ikenoue, T., Seki, T. \& Tsuji, T. (2005). Identification and preliminary SAR studies of $(+)$-geodin as a glucose uptake stimulator for rat adipocytes. J Antibiot (Tokyo) 58, 583-589.

Serra, R., Cabanes, F. J., Perrone, G., Castella, G., Venancio, A., Mule, G. \& Kozakiewicz, Z. (2006). Aspergillus ibericus: a new species of section Nigri isolated from grapes. Mycologia 98, 295-306.

Smedsgaard, J. (1997). Micro-scale extraction procedure for standardized screening of fungal metabolite production in cultures. J Chromatogr A 760, 264-270.

Swofford, T. (2000). PAUP*: Phylogenetic analysis using parsimony (and other methods), version 4.0., Sunderland, MA: Sinauer Associates.

Turner, W. B. (1965). The production of trypacidin and monomethylsulochrin by Aspergillus fumigatus. J Chem Soc (Perkin 1) 6658-6659.

Varga, J., Kevei, F., Debets, F., Kozakiewicz, Z. \& Croft, J. H. (1994). Mitochondrial DNA restriction fragment length polymorphisms in field isolates of the Aspergillus niger aggregate. Can J Microbiol 40, 612-621.

Varga, J., Kevei, F., Hamari, Z., Tóth, B., Téren, J., Croft, J. H. \& Kozakiewicz, Z. (2000). Genotypic and phenotypic variability among black aspergilli. In Integration of Modern Taxonomic Methods for Penicillium and Aspergillus Classification, pp. 397-411. Edited by R. A. Samson \& J. I. Pitt. Amsterdam: Harwood Academic. 
Varga, J., Kocsubé, S., Tóth, B., Frisvad, J. C., Perrone, G., Susca, A., Meijer, M. \& Samson, R. A. (2007). Aspergillus brasiliensis sp. nov., a biseriate black Aspergillus species with world-wide distribution. Int J Syst Evol Microbiol 57, 1925-1932.
White, T. J., Bruns, T., Lee, S. \& Taylor, J. (1990). Amplification and direct sequencing of fungal ribosomal RNA genes for phylogenetics. In PCR Protocols: a Guide to Methods and Applications, pp. 315-322. Edited by M. A. Innis, D. H. Gelfand, J. J. Sninsky \& T. J. White. San Diego: Academic Press. 